\title{
El derecho de gentes *
}

\author{
JOHN RAWLS \\ Harvard University, Cambridge
}

El objeto de este ensayo es la extensión al ambito de las relaciones internacionales de la teoría de la justicia como cquidad formulada por el autor en sus anteriores escritos. Así, el Derecho de Gentes es concebido como una familia de conceptos políticos ligada a principios de derecho, justicia y bien común, todo lo cual especifica el contenido de una concepción liberal de la justicia formulada para abarcar y ser aplicada al derecho internacional. Los derechos humanos constituyen un elemento central de esta construccion en la medida en que establecen los límites morales al pluralismo entre los pueblos.

Uno de los propósitos de este artículo ** es sugerir - de manera breve, pues no puedo hacer otra cosa - que el derecho de gentes ${ }^{1}$ puede ser desarrollado a partir de ideas liberales de justicia similares, pero más generales que la que denominé ujusticia como equidad" y presenté en mi libro Una Teoría de la Justicia en 1971. Por derecho de gentes entiendo una concepción política del derecho y la justicia ${ }^{2}$ que se aplique a los principios y preceptos del derecho y la práctica

* Este artículo forma parte de la versión española de la obra de Stephen Schute y Susan Ilurley (eds.) On Human Rights, que será publicada próximamente por Fiditorial Trotta, a la que agradecemos su autorización para anticipar la presente traducción, realizada por Heruando Valencia-Villa.

* Estoy en deuda con muchas personas que me han ayudado en este trabajo. He indicado las deudas especificas en las notas a pie de página. Me gustaría reconocer deudas más generales con Ronald Dworkin y Thomas Nagel, por las discusiones en torno a mis anteriores tentativas de tratar el derecho do gentes en sus seminarios de la Universidad de Nueva York en el otoño de 1990 y 1991 ; con T. M. Scanlon y Joshua Cohen, por sus valiosas criticas; con Michael Coyle y Philip Soper, por su instructiva correspondencia; y, como siempre, con Burton Dreben. Estoy especialmente agradecido a Erin Kelly, quien ha leido los borradores de este texto y ha sugerido muchas correcciones, que he adoptado en su mayoria. Sus críticas y sugerencias han sido esenciales en la adccuada presentación de mi argumentación en la sección IV.

' La expresión «derecho de gentes» (Low of Peoples) proviene del tradicional jus gentium, y el sentido en que lo empleo es el más próximo a la locución jus gentium intra se (derecho de gentes entre si). En este sentido se refiere a lo que todas las leyes de los pueblos tenían en común. Véáse R. J. Vincent, Human Rights and Intemational Relations, Cambridge, Cambridge University Press, 1986, p. 27. Si estas leyes forman un conjunto de principios de justicia aplicables a todos los pueblos en todas las latitudes, se tiene un significado similar al que yo le doy al derecho de gentes.

' Una concepción política de la justicia tiene las tres características siguientes: 1) está diseñada para las instituciones políticas, económicas y sociales básicas; en el caso de la sociedad doméstica, para su estructura fundamental, y en el presente caso, para el derecho y las prácticas de la sociedad de los pueblos; 2) aparece como independiente de cualquier doctrina religiosa, filosófica o moral comprehensiva, $y$ aunque puede derivarse de o relacionarse con alguna de tales doctrinas, no está construida de ese modo; 3) su contenido se expresa bajo la forma de ciertas ideas fundamentales implícitas en la cultura política pública de una sociedad liberal. Veáse mi Political Liberalism, Nueva York, Columbia 
internacionales. En la sección 58 del trabajo citado yo indicaba cómo de la justicia como equidad puede ser deducido el derecho de gentes, con el propósito específico de tratar varias cuestiones relativas a la guerra justa. En este artículo, mi esquema de tal derecho se extiende a otros aspectos e incluye una presentación de la función de los derechos humanos. Si bien la idea de justicia empleada aquí es más general que la justicia como equidad, se encuentra relacionada con la idea del contrato social: el procedimiento de construcción y los pasos de la indagación son casi los mismos en ambos casos.

Un propósito adicional es plantear la sustentación del liberalismo político una vez que una concepción política liberal de la justicia se extiende al derecho de gentes. En particular, nos preguntamos: ¿Qué forma adopta la tolerancia de las sociedades no liberales en este caso? Ciertamente, los regímenes tiránicos y dictatoriales no pueden ser aceptados de buen grado como miembros de una razonable sociedad de las naciones. Pero de igual modo no a todos los regímenes puede exigírseles de manera razonable que sean liberales. De lo contrario, el derecho de gentes no expresaría el principio liberal de tolerancia frente a otras formas razonables de ordenar la sociedad, ni avanzaría en su esfuerzo por hallar un fundamento compartido para el acuerdo entre pueblos razonables. Del mismo modo que el ciudadano en una sociedad liberal debe respetar las doctrinas religiosas, filosóficas y morales de las otras personas en tanto sean mantenidas de conformidad con una razonable concepción política de la justicia, una sociedad liberal debe respetar a las demás sociedades organizadas según doctrinas comprehensivas, en la medida en que sus instituciones políticas y sociales cumplan ciertas condiciones conducentes a que la sociedad se adhiera a un razonable derecho de gentes.

Más especificamente, nos preguntamos: ¿Dónde deben trazarse los límites razonables de la tolerancia? Puede ocurrir que una sociedad no liberal bien ordenada acepte el mismo derecho de gentes que aceptan las sociedades liberales bien ordenadas. Entiendo por bien ordenada una sociedad pacífica y no expansionista, cuyo sistema legal satisface ciertos requisitos de Icgalidad a los ojos de su propio pueblo y que, en consecuencia, hace honor a los derechos humanos fundamentales (sección IV). Una modalidad de sociedad no liberal que satisface estas condiciones es la que, a falta de mejor denominación, llamo sociedad jerárquica bien ordenada. Este ejemplo ilustra cómo aunque cualquier sociedad debe honrar los derechos humanos fundamentales, no es necesario que sea liberal, lo cual resulta esencial para nuestro argumento. E indica también el papel de los derechos humanos como parte de un razonable derecho de gentes.

University Press, 1993, pp. 11-15 (hay trad. cast.: El Liberalismo Polftico, Barcelona, Crítica/Grijalbo Mondadori, 1996). 


\section{Cómo una doctrina del contrato social tiene alcance universal}

Empiezo por explicar la forma en la cual una doctrina del contrato social, con su procedimiento de construcción, tiene alcance universal.

Toda sociedad debe tener una concepción acerca de cómo está relacionada con las otras sociedades y cuál ha de ser su conducta hacia ellas. Vive con cllas en el mismo mundo y salvo en el caso especial de una sociedad aislada del resto, que es cosa del pasado, debe formular ciertos ideales y principios para orientar sus políticas hacia otros pueblos. Al igual que la justicia como equidad, la concepción liberal más general que tengo en mente - tal como se especifica en la sección IIempieza con el caso de una sociedad liberal democrática, hipotéticamente cerrada y autosuficiente, y se refiere tan sólo a los valores políticos y no a toda la vida. La cuestión radica en cómo esta concepción puede extenderse de manera convincente a las relaciones de una sociedad con las otras sociedades para sustentar un razonable derecho de gentes. En ausencia de esta extension al derecho de gentes, una concepción liberal de la justicia política parecería hístoricista y se aplicaría sólo a sociedades con instituciones políticas y cultura de signo liberal. Al argumentar en favor de la justicia como equidad y de concepciones liberales más generales resulta esencial mostrar que no es así.

El problema del derecho de gentes es apenas uno de los que plantea la extensión de estas ideas de justicia. Existe el problema adicional de extender estas ideas a las futuras generaciones, lo cual implica la cuestión del ahorro justo. Del mismo modo, puesto que las ideas de justicia consideran a las personas como miembros normales y activos de la sociedad a lo largo de una vida cabal, cuando se tienen las capacidades requeridas para ello surge el problema de qué es debido a quienes no cumplen esta condición temporal o permanentemente, lo cual plantea varias cuestiones de justicia en la asistencia médica y sanitaria. Finalmente, existe el problema de lo que se debe a los animales y al resto de la naturaleza.

Eventualmente, nos gustaría responder a todas estas cuestiones, pero dudo que ello sea posible dentro del ámbito de estas ideas de justicia entendidas como concepciones políticas. En el mejor de los casos, puede haber respuestas razonables a los primeros tres problemas de extensión: a las otras sociedades, a las generaciones y a ciertos aspectos de la asistencia médica. Respecto de los problemas no atendidos por estas ideas liberales de justicia, debemos señalar varias cosas. Una es que la idea de justicia política no cubre todo y no deberíamos esperar que así fuese. O el problema puede ser de justicia política, pero ninguna de estas ideas resulta correcta para la cuestión de que se trata. Para saber cuán profunda es la falla hay que esperar a que el punto sea examinado, pero no deberíamos esperar que estas ideas, o cualquier versión de la justicia política, se ocupen de todos los asuntos.

Volvamos a nuestro problema de extender ideas liberales de justicia, similares pero más generales que la justicia como equidad, al derecho de gentes. Hay un claro contraste entre estas y otras versiones familiares en cuanto a su alcance universal. Tomemos, por ejemplo, las doctrinas de Leibniz o Locke, que son uni- 
versales tanto en su fuente de autoridad cuanto en su formulación. Su fuente es la autoridad de Dios o la razón divina y sus principios están planteados de manera que se aplican a todos los seres razonables en todas partes. La doctrina de Leibniz es una ética de la creación. Contiene la idea de la moral como la imitatio Dei y se aplica directamente a nosotros como criaturas de Dios que están dotadas de razón. En la doctrina de Locke, Dios tiene autoridad legítima sobre toda la creación y la ley natural, aquella parte de la ley divina que puede ser conocida por nuestra razón natural, tiene autoridad en todas partes y obliga a todos los pueblos.

Visiones filosôficas más familiares, como el intuicionismo racional, el utilitarismo clásico y el perfeccionismo, también se encuentran formuladas de mancra general para ser directamente aplicadas a nosotros en todos los casos. Aunque no tienen base teológica, digamos que su fuente de autoridad es la razón humana o un dominio independiente de valores morales o algún otro fundamento de validez universal. En todas estas perspectivas, la universalidad de la doctrina es la consecuencia directa de su fuente de autoridad y de su estilo de formulación.

En contraste, un enfoque constructivista como la justicia como equidad e ideas liberales más generales no empiezan en principios universales con autoridad en todos los casos ${ }^{3}$. En la justicia como equidad, los principios de justicia para la estructura básica de la sociedad no son aplicables como principios generales: no se aplican a todos los sujetos, ni a las iglesias y universidades, o a las estructuras básicas de todas las sociedades o al derecho de gentes. Más bien están formulados mediante un procedimiento razonable en el cual los actores racionales adoptan principios de justicia para cada sujeto en la medida en que resulta relevante. En una situación típica, una doctrina constructivista procede a escoger una serie de sujetos y empieza con principios de justicia política para la estructura básica de una sociedad democrática cerrada y autosuficiente. Hecho esto, avanza hacia principios para las reivindicaciones de las generaciones futuras, en lo externo, hacia principios para el derecho de gentes, y en lo interno, hacia principios para cuestiones sociales especiales. En cada ocasión, el procedimiento constructivista se modifica para ajustarse al sujeto en cuestión. A su debido tiempo, todos los principios están disponibles, incluso aquellos requeridos para los deberes y las obligaciones políticas de individuos y asociaciones ${ }^{4}$. Así, una doctrina liberal constructivista es universal en su alcance una vez que se extiende hasta ofrecer principios para todos los sujetos políticamente relevantes, incluido un derecho de gentes para el más comprehensivo de los sujetos: la sociedad política de los pueblos. Su autoridad descansa en los principios y las concepciones de la razón práctica, pero siempre en aquellos aplicables a diferentes sujetos en la medida en que se presenten, y siempre bajo

"En este y en los dos próximos párrafos me baso en la primera sección de «Basic Structure as Subject» (1978), en Political Liberalism.

- Para un ejemplo detallado de cómo puede hacerse esto en el caso de la secuencia de cuatro etapas de la posición original, la asamblea constituyentc, el órgano legislativo y los tribunales, veáse A Theory of Justice, Cambridge, Harvard University Press, 1971, pp. 195-201 (hay trad. cast.: Teoria de La Justicia, Madrid, Fondo de Cultura Económica, 1979). Una exposición más breve se encuentra en *Basic Liberties and Their Priority» (1982), en Political Liberalism. 
el supuesto de que cstos principios sean respaldados de modo reflexivo por los agentes razonables a los cuales se aplican los principios correspondientes.

A primera vista, una tal doctrina constructivista parece desesperadamente asistemática. Pues ¿cómo se unen los principios aplicables a diferentes casos? ¿Y por qué procedemos a través de la serie de casos conforme a un cierto orden y no a otro? El constructivismo supone, empero, que hay formas de unidad distintas de aquellas definidas por principios generales integrados en un esquema consistente. La unidad también puede provenir de una sccucncia apropiada de casos y de la suposición de que las partes en una posición original, como yo la he llamado, proceden a través de la secuencia en el entendido de que los principios para el sujeto de cada convenio posterior han de subordinarse a los principios para sujetos de todos los convenios anteriores o coordinarse con ellos según ciertas reglas de prioridad. Ensayaré una secuencia particular y señalaré sus méritos sobre la marcha. No hay garantía anticipada de que sea la secuencia más apropiada, por lo cual puede ser necesario recurrir una y otra vez al método de «ensayo y error».

Al desarrollar una concepción de la justicia para la estructura básica o para el derecho de gentes o para cualquier sujeto, el constructivismo no considera que la pertinencia de diferentes principios en diferentes casos depende tan sólo de la variación en el número de personas. Que las familias sean menores que las democracias constitucionales no explica por qué se aplican a ellas diferentes principios. Más bien se trata de que la distinta estructura del sistema social, y el propósito y la función de sus varias partes y de la forma en que se ajustan unas a otras, explican por qué hay diferentes principios para diferentes clases de sujetos. En consecuencia, es característico de una idea constructivista de justicia considerar la naturaleza y la finalidad distintivas de los elementos de la sociedad y de la sociedad de los pueblos, así como demandar a las personas, en un dominio donde los demás principios las dejan en libertad, que actúen de conformidad con principios diseñados para ajustarse a sus roles peculiares. Como veremos al tratar del derecho de gentes, estos principios son identificados en cada caso por los agentes racionales equitativa o razonablemente situados frente al caso en cuestión. No se derivan de principios absolutamente generales como el de utilidad o el de perfeccionismo.

\section{Tres cuestiones preliminares}

Antes de mostrar cómo puede realizarse la extensión del derecho de gentes me ocupo de tres asuntos preliminares. Primero hay que distinguir dos partes en la justicia como equidad o en cualquier otra concepción liberal y constructivista de la justicia. Una parte se aplica a las instituciones domésticas de las sociedades democráticas, su régimen y estructura básica y los deberes y las obligaciones de los ciudadanos. La otra parte es aplicable a la sociedad de sociedades políticas $y$, por consiguicnte, a las relaciones políticas entre los pueblos ${ }^{5}$. Después de que

\footnotetext{
${ }^{5}$ Por puehlo cntiendo las personas y sus dependientes que forman un cuerpo organizado con sus propias instituciones políticas y su gobiemo. En las sociedades democráticas las personas serán ciudadanos y en las jerárquicas y otras, miembros.
} 
los principios de justicia han sido adoptados para la justicia doméstica, la idea de la posición original se emplea de nuevo en el siguiente nivel superior ${ }^{6}$. Como antes, las partes tienen un carácter representativo, pero ahora representan pueblos cuyas instituciones básicas satisfacen los principios de justicia escogidos en el primer nivel. Empezamos con la familia de las naciones, cada una bien ordenada por algún principio liberal que cumple ciertas condiciones (la justicia como equidad es un ejemplo), y entonces buscamos principios para gobernar sus relaciones. Aquí menciono solamente la primera etapa de formulación del derecho de gentes. Como veremos en la sección IV, también debemos desarrollar principios que gobiernen las relaciones entre las sociedades liberales y lo que llamaré sociedades jerárquicas. Sucede que las sociedades liberales y jerárquicas pueden coincidir en el mismo derecho de gentes y así éste no depende de aspectos peculiares de la tradición occidental.

Bien puede objetarse que proceder así es aceptar el Estado en su concepción tradicional, con todos sus familiares poderes de soberanía. Estos poderes incluyen, en primer lugar, el derecho de hacer la guerra en desarrollo de las políticas estatales - la continuación del intcrcambio político por otros medios según Clausewitza fin de cumplir los objetivos correspondientes a los intereses racionales y prudentes del Estado ${ }^{7}$. Incluyen, en segundo lugar, el derecho del Estado a disponer a su antojo de las gentes dentro de sus fronteras. La objeción es infundada por esta razón. En el primer uso de la posición original, la sociedad doméstica se ve cerrada, pues haccmos abstracción de las relaciones con otras sociedades. No hay necesidad de fuerza armada y la cuestión del derecho del gobierno a prepararse militarmente no se plantea o seria resuelta en forma negativa. Los principios de la justicia doméstica autorizan una fuerza de policía para mantener el orden interno, pero ésa es otra cuestión, $\mathrm{y}$ aunque tales principios son consistentes con un derecho calificado a librar la guerra en el seno de la sociedad de las naciones, ellos de suyo no sustentan ese derecho. Tal cosa depende del propio derecho de gentes en vías de formulación. $Y$ como vemos, este derecho también restringirá la soberanía interna del Estado, es decir, su derecho a disponer de la población dentro de sus fronteras.

En consecuencia, en esta búsqueda del derecho de gentes importa advertir que un gobierno, en tanto organización política de su pueblo, no es como antes el autor de su propio poder. Los poderes de guerra de los gobiernos, sin importar lo que deberían ser, son tan sólo los aceptables dentro de un razonable derecho de gentes. Presumir la existencia de un gobierno en el cual un pueblo está domés-

\footnotetext{
"Véase Theory, p. 378, donde se describe brevemente este proceso.

' Sería injusto con Clausewitz omitir que para él los intereses estatales pueden incluir fines morales regulativos de cualquier clase, de suerte que el fin de la guerra puede ser la defensa de las sociedades demoeráticas contra los regímenes liránicos, en cierto modo como en la Segunda Guerra Mundial. Para Clausewitz los fines de la política no son parte de la teoría de la gucrra, aunque están siempro presentes y pueden afectar la conducción de la guerra. Véanse las instructivas observaciones de Peter Parct, «Clausewitz», en Peter Paret (cd.), The Makers of Modom Strategy, Princeton, Princeton University Press, 1986, pp. 209-213. Mi propio punto de vista define la razón de Estado al estilo de Federico el Grande, $O$ asi lo plantea Gerhard Ritter en Frederick the Great, Berkeley, California University Press, 1968, cap. 10 y p. 197.
} 
ticamente organizado con instituciones de justicia fundamental no significa prejuzgar sobre estas cuestiones. Debemos reformular los poderes soberanos a la luz de un razonable derecho de gentes y eliminar el derecho a la guerra y el derecho a la autonomía interna que han sido parte del derecho internacional positivo en los dos siglos y medio posteriores a la Guerra de los Treinta Años, como clementos del clásico sistema interestatal ${ }^{8}$.

Más aún, estas ideas concuerdan con un dramático giro en la comprensión actual del derecho internacional. Desde la Segunda Guerra Mundial, el derecho internacional se ha hecho mucho más exigente que en el pasado. Tiende a restringir el derecho del Estado a librar la guerra a los casos de legítima defensa, lo cual permite la seguridad colectiva, y tiende también a limitar el derecho del Estado a la soberanía interna ${ }^{\circ}$. La función de los derechos humanos se relaciona de manera más obvia con este último cambio, como parte del esfuerzo por ofrecer la definición y los limites adecuados de la soberanía interior del Estado, aunque no está desvinculado del primer aspecto. Aquí dejo a un lado las numerosas dificultades de interpretación de tales derechos y sus límites, pues considero suficientemente claros su significado general y sus perspectivas. Lo esencial es que nuestra elaboración del derecho de gentes se ajuste a estos dos cambios fundamentales y les dé una sustentación adecuada.

El segundo asunto preliminar concierne a la segunda pregunta: Al formular el derccho de gentes, ipor qué empezamos, como dije antes, por aquellas sociedades bien ordenadas según criterios liberales algo más generales que la justicia como equidad? ¿No sería mejor empezar por el mundo como una totalidad, con una posición original global, por así decirlo, y discutir si y en qué forma debería haber Estados o pueblos? Algunos escritores, que mencionaré más adelante, han estimado que una perspectiva constructivista del contrato social debería proceder de esta manera, pues ella entraña una adecuada universalidad desde el comienzo.

Pienso que no existe, en principio, una respuesta clara a esta pregunta. Deberíamos ensayar varias alternativas y ponderar sus más y sus menos. Ya que al plantear la justicia como equidad empiezo por la sociedad doméstica, continuaré como si lo hecho hasta ahora fuera más o menos atinado. Entonces me sirvo de los pasos tomados hasta ahora, pues parecen ofrecer un punto de partida apropiado para la extensión al derecho de gentes. Una razón adicional para proceder asi consiste en que los pueblos como cuerpos organizados por sus gobiernos existen hoy de algún modo en todo el mundo. Históricamente hablando, todos los principios y criterios propuestos por el derecho de gentes, para ser factibles, tienen que ser aceptables para la opinión pública ponderada y reflexiva de los pueblos y sus gobiernos.

Supóngase entonces que somos, aunque no lo seamos, miembros de una sociedad bien ordenada. Nuestras convicciones acerca de la justicia son casi las mismas que las de los ciudadanos, si los hay, de la familia de naciones bien ordenadas

\footnotetext{
${ }^{8}$ Charles Beitz caracteriza estos poderes como propios de lo que llama moralidad de los Estados en su Political Theoy and Intemational Retations, Princeton, Princeton University Press, 1980, segunda parte. Sostiene que ellos dependen de una erronca analogía entre individuos y Estados.

- Stanley IIoffman, Janus and Minerva, Botilder, Westview Press, 1987, p. 374.
} 
según concepciones liberales de justicia y en condiciones sociales e históricas similares a las nuestras. Ellos tienen idénticas razones para afirmar su estilo de gobierno que nosotros el nuestro. Este entendimiento común de las sociedades liberales ofrece un punto de partida idóneo para la extensión al derecho de gentes.

Finalmente, hago notar la distinción entre el derecho de gentes y el derccho de las naciones o derecho internacional. Este último es un orden legal existente o positivo, si bien incompleto, pues adolece, por ejemplo, de un efectivo sistema de sanciones como el que caracteriza normalmente al derecho doméstico. El derecho de gentes, en cambio, es una familia de conceptos políticos con principios de derecho, justicia y bien común, que especifica el contenido de una concepción liberal de la justicia aplicable al derecho internacional. Proporciona los conceptos y principios por los cuales ese derecho debe ser juzgado.

Esta distinción entre el derecho de gentes y el derecho de las naciones debería ser directa, pues no es más oscura que la existente entre los principios de justicia que se aplican a la estructura básica de la sociedad doméstica y las instituciones políticas, sociales y legales existentes que hacen realidad aquella estructura.

\section{La extensión a las sociedades liberales}

Atendidas las tres cuestiones preliminares, paso a la extensión de las ideas liberales de justicia al derecho de gentes. Entiendo que dichas ideas contienen tres elementos principales: a) una lista de ciertos derechos, libertades y oportunidades fundamentales (de las familias a las democracias constitucionales); $b$ ) una alta prioridad para tales libertades fundamentales, especialmente con respecto a reivindicaciones del bien general y de valores perfeccionistas, y c) medidas para asegurar a todos los ciudadanos los medios de uso efectivo de sus libertades. La justicia como equidad es típica de estas concepciones, pero sus cualidades igualitarias son más fuertes. Hasta cierto punto, las ideas liberales más generales carecen de las tres cualidades igualitarias del justo valor de las libertades políticas, de la justa igualdad de oportunidades y del principio de diferencia. Estas caracteristicas no son necesarias para la construcción de un razonable derecho de gentes $y$, al no asumirlas, nuestra versión posee mayor generalidad.

Hay dos etapas principales en la extensión al derecho de gentes y cada etapa tiene dos pasos. La primera etapa es la de la teoria ideal o de estricto cumplimiento, y en ella nos apoyamos por entero, salvo expresa indicación de lo contrario. Ello significa que todas las partes en los acuerdos celebrados dan estricto cumplimiento a los principios y conceptos relevantes, y que existen las condiciones favorables requeridas por las instituciones liberales o jerárquicas. Nuestro primer objetivo es determinar lo que un razonable derecho de gentes, al cual se da pleno cumplimiento, requeriría y establecería en este caso.

Para hacer operativa nuestra versión, suponemos que hay sólo dos clases de sociedades domésticas bien ordenadas: liberales y jerárquicas. En el primer paso, discuto el caso de las sociedades democráticas liberales bien ordenadas, lo cual conduce a la idea de una sociedad política bien ordenada de sociedades de pueblos 
democráticos. Me ocupo luego de sociedades bien ordenadas y justas, de naturaleza frecuentemente religiosa y sin separación entre iglesia y Estado. Sus instituciones políticas prevén una justa jerarquía consultiva, como la llamaré, mientras sus instituciones sociales básicas satisfacen una idea de la justicia que traduce una adecuada concepción del bien común. Para nuestra versión del derecho de gentes resulta fundamental que ella sea aceptada tanto por las sociedades liberales como por las jerárquicas. Unas y otras son miembros regulares de una sociedad bien ordenada de los pueblos justos del mundo.

La segunda etapa es la de la teoría no ideal e incluye también dos pasos. El primer paso es el de la teoría del incumplimiento. Se trata del predicamento en que se hallan las sociedades justas, democráticas y jerárquicas, cuando se enfrentan a Estados que rehúsan cumplir un razonable derecho de gentes. El segundo paso de esta segunda etapa tiene que ver con las condiciones adversas y plantea un problema diferente: cómo las sociedades más pobres y menos tecnológicamente avanzadas del mundo pueden alcanzar condiciones históricas y sociales que les permitan establecer instituciones justas y funcionales, liberales o jerárquicas. En la vida real, la teoría no ideal es de gran importancia, pues se enfrenta a los problemas que afrontamos cada día. Empero, por razones de espacio, diré muy poco al respecto (secciones VI y VII).

Antes de examinar la extensión, conviene asegurarse de que la posición original con el velo de ignorancia es un instrumento de representación para las sociedades liberales. En el primer uso de la posición original, su función como mecanismo de representación significa que da forma a los que consideramos - usted y yo, aquí y ahora- ${ }^{10}$ como condiciones justas para las partes, en tanto representantes de los ciudadanos libres e iguales, a fin de precisar los términos de cooperación que regulan la estructura básica de st sociedad. Puesto que tal posición incluye el velo de ignorancia, también da forma a lo que consideramos como restricciones aceptables de las razones para adoptar una comunión política de la justicia. Por consiguiente, la concepción que las partes adoptarían identifica la concepción de justicia que vemos — usted y yo, aqui y ahora - como justa y asistida de las mejores razones.

Tres condiciones son esenciales: primero, la posición original representa justa o razonablemente a las partes o ciudadanos; segundo, los representa como racionales, y tercero, los representa al decidir entre principios disponibles por razones adecuadas. Comprobamos que estas tres condiciones se cumplen al observar que los ciudadanos están, en efecto, justa o razonablemente representados en virtud de la situación de igualdad y simetría de sus representantes en la posición original. A continuación, los ciudadanos son representados como racionales en virtud del esfucrzo de sus representantes en realizar sus intereses esenciales como personas. Finalmente, son representados al decidir por razones apropiadas: el velo de ignorancia impide a sus representantes invocar razoncs inadccuadas, pucsto que sc trata de representar a los ciudadanos como personas libres e iguales.

${ }^{10}$ Nótese que «usted y yow somos saquí y ahora» ciudadanos de la misma sociedad democrática liberal y elaboramos la concepción liheral de la justicia en cuestión. 
En el siguiente nivel, cuando la posición original se emplea para extender una concepción liberal al derecho de gentes, es un dispositivo de representación, por cuanto da forma a lo que consideramos - usted y yo, aquí y ahora- ${ }^{11}$ como condiciones justas bajo las cuales las partes, esta vez como representantes de sociedades bien ordenadas según concepciones liberales de justicia, definen el derecho de gentes y los justos términos de su cooperación.

La posición original es un mecanismo de representación porque, al igual que antes, pueblos libres e iguales son representados a la vez como razonablemente situados y como racionales, al decidir de acuerdo con razones apropiadas. Como representantes de pueblos democráticos, las partes están simétricamente situadas y por tal razón los pueblos que ellas representan están razonablemente representados. Más aún, las partes deliberan entre principios disponibles para cl derecho de gentes y hacen referencia a los intereses fundamentales de las sociedades democráticas en concordancia con los principios liberales de justicia doméstica. Y, finalmente, las partes están bajo un velo de ignorancia: no saben, por ejemplo, el tamaño del territorio o la población, o la fuerza relativa del pueblo cuyos intereses fundamentales representan. Aunque saben qué condiciones razonablemente favorables hacen posible la democracia, ignoran la extensión de sus recursos naturáles o su nivel de desarrollo económico u otra información relevante. Estas condiciones dan forma a lo que, como miembros de sociedades bien ordenadas por concepciones liberales de justicia, aceptaríamos como justo - aquí y ahora- para definir los términos de cooperación entre pueblos que, en tanto pueblos, se consideran libres e iguales. Usamos la posición original como instrumento de representación en el segundo nivel, como hicimos en el primero.

Supongo que formular el derecho de gentes para sociedades liberales democráticas sólo se traducirá en la adopción de ciertos principios familiares de justicia, y permitirá varias formas de asociación cooperativa entre pueblos democráticos y no un Estado mundial. Sigo aquí la orientación de Kant en La Paz Perpetua (1795), cuando estima que un gobierno mundial - por el cual entiendo un régimen político unificado, con los poderes legales normalmente atribuidos a los gobiernos centrales- sería un despotismo global o un frágil imperio desgarrado por frecuentes luchas civiles, pues diferentes pueblos y regiones tratarían de conseguir autonomía política ${ }^{12}$. De otra parte, bien puede ocurrir, como sugiero más adelante, que haya muchas clases difcrentes de organizaciones sometidas al derecho de los pueblos

"En este caso custed y yo» somos ciudadanos de sociedades democráticas liberales, pero no de la misma.

iz Kant dice que la idea de derecho internacional presupone la existencia separada de Estados vecinos independientes, y que si bien esta condición es en sí un estado de guerra (a menos que una unión federativa evite la apertura de hostilidades), esto resulta racionalmente preforible a la amalgama de Estados bajo un poder superior, la cual derivaría hacia una monarquia universal, de suerte que las leyes perderían en vigor lo que el gobiemo ganaría en extensión; de ahí que una condición de despotismo sin alma caiga en la anarquía tras dispersar las semillas del bien. Esta postura frente a la monarquía universal era compartida por otros escritores del siglo xvir. Véase, por ejemplo, Hume, wOf the Balance of Powcr» (1752). F. H. Hinsley, Power and Pursuit of Peace, Cambridge, Cambridge University Press, 1966, p. 162, también menciona a Monstesquieu, Voltaire y Gibbon, además de una instructiva discusion sobre Kant en el cap. 4. Vése también Patrick Riley, Kant's Political Philonophy, 
democráticos, encargadas de regular la cooperación entre ellos y obligadas a cumplir ciertos deberes. Algunas de estas organizaciones, como las Naciones Unidas, pueden estar investidas de autoridad para condenar a las instituciones domésticas que violen los derechos humanos $y$, en ciertos casos graves, para castigarlas mediante sanciones económicas o incluso intervención militar. El ámbito de estos poderes es el de todos los pueblos y se extiende a sus asuntos domésticos.

Si esto es correcto, creo que los principios de justicia entre pueblos libres y democráticos incluirían ciertos postulados reconocidos desde hace largo tiempo como integrantes del derecho de gentes, entre ellos los siguientes:

1. Los pueblos (organizados por sus gobiemos) son libres e independientes y su libertad e independencia han de ser respetadas por los otros pueblos.

2. Los pueblos son iguales en tanto partes de sus propios convenios.

3. Los pueblos tienen el derecho a la legítima defensa pero no el derecho a la guerra.

4. Los pueblos tienen un deber de no intervención.

5. Los pueblos deben cumplir los tratados y acuerdos.

6. Los pueblos deben respetar ciertas restricciones específicas en la conducción de la guerra (siempre que ella se libre en legitima defensa); y

7. Los pueblos deben respetar los derechos bumanos.

Por supuesto, esta declaración de principios es incompleta; otros principios deberian agregarse. Además, tales postulados demandan mucha explicación e interpretación, y algunos de ellos resultan superfluos en una sociedad de pueblos democráticos bien ordenados como, por ejemplo, el sexto sobre la conducción de la guerra y el séptimo sobre derechos humanos. La cuestión central es que, supuesta la idea de una sociedad de pueblos democráticos libres e independientes, que están dispuestos a reconocer ciertos principios básicos de justicia política para gobernar su conducta, tales principios constituyen el estatuto de su asociación ${ }^{13}$. Obviamente, un principio como el cuarto, sobre no intervención, tendrá que ser cualificado de manera general. Aunque aplicable a una sociedad de pueblos democráticos bien ordenados que respeten los derechos humanos, no funciona en el caso de sociedades desordenadas, en las cuales son endémicas las guerras y las violaciones graves de los derechos humanos. De igual manera, el derecho a la independencia y el derecho a la autodeterminación operan dentro de ciertos límites que deben ser señalados de manera general por el derecho de gentes. Así, ningún pueblo tiene el derecho a la autodeterminación, o a la secesión, a costa del sometimiento de otro pueblo ${ }^{14}$; ni puede un pueblo protestar por la condena de la sociedad mundial cuando sus instituciones domésticas violan los derechos humanos de ciertas minorías que viven en su territorio. Su derecho a la independencia no

Towanda, Rowman and Litte Field, 1983, caps. 5 y 6 . Thomas Nagel en su Equality and Pariality, Oxford, Oxford University Press, 1991, pp. 169 y 174, respalda esta conclusión con poderosas razones.

"5 Vease Terry Nardin, Law, Morality and the Relations of States, Princeton, Princeton University Press, 1983, p. 269.

i Un ejemplo claro sobre la secesión concierne a si el Sur tenia derecho a separarse de los Estados Unidos ca 1860 y 1861 . Según este criterio, no tenía tal derecho, pues se separaba para perpetuar 
es un escudo contra esa condena o incluso contra la intervención coercitiva de otros pueblos en casos graves.

Habrá también principios para formar y regular federaciones o asociaciones de pueblos, y criterios de equidad para el comercio y otros arreglos cooperativos. Debe haber ciertas disposiciones para asistencia recíproca entre los pueblos durante tiempos de hambruna y sequía, y si fucre factible, como debería serlo, medidas para asegurar que en todas las socicdades liberales razonablemente desarrolladas sean atendidas las necesidades básicas de la población ${ }^{15}$. Estas disposiciones establecerán deberes de asistencia en ciertas situaciones y serán tanto más severas cuanto más grave sea el caso.

Una importante función del gobierno, no importa cuán arbitrarias puedan parecer las fronteras de una sociedad desde un punto de vista histórico ${ }^{16}$, es la de representante y agente efectivo de un pueblo al responsabilizarse por su territorio y por el tamaño de su población, al igual que por el mantenimiento de la integridad del ambiente y su capacidad para sustentar a la población. La idea aquí apela a la institución de la propiedad: a menos que un agente se responsabilice por la conservación de un recurso y sufra una pérdida por no hacerlo, ese bien tiende a deteriorarse. En este caso, el recurso es el territorio del pueblo y su capacidad para sostenerlo a perpetuidad; el agente es el pueblo mismo, políticamente organizado. Éste debe reconocer que no puede eludir la responsabilidad de cultivar su tierra y conservar sus recursos naturales frente a la conquista bélica o la migración hacia el territorio de otro pueblo sin su consentimiento ${ }^{17}$.

Estas observaciones corresponden a la teoría ideal e indican algunas de las responsabilidades de los pueblos en una sociedad justa de sociedades liberales bien ordenadas. Puesto que las fronteras de los pueblos frecuentemente son el resultado histórico de la violencia y la agresión, y algunos pueblos están injustamente sometidos a otros, el derecho de gentes en su parte no ideal debería en lo posible contener principios y criterios $\rightarrow$ al menos guías - para tratar estos temas.

Para completar este esbozo del derecho de gentes sólo para sociedades liberales bien ordenadas, consideremos bajo qué condiciones podemos aceptar de modo razonable esta parte del derecho de gentes y encontrarla justificada.

Existen dos condiciones además de los tres requisitos anotados al discutir la posición original como mecanismo de representación. Estos requisitos eran: que

la institución domestica de la esclavitud, que era una gravísima violación de los derechos humanos y se extendía a la mitad de la población.

15 Por necesidades básicas entiendo aquellas que deben satisfacerse si los ciudadanos han de beneficiarse de los derechos, las libertades y las oportunidades de su sociedad. Incluyen tanto los medios econónicos como los dercchns y las lihertades institucionales.

${ }^{16}$ Del hecho de que las fronteras sean históricamente arbitrarias no se sigue que su función en el derecho de gentes no pueda ser justificada. La arbitrariedad histórica de las fronteras entre los Estados de la Unión ameticana no es un argumento a favor de la eliminación de nuestro sistema federal, en una u otra forma. Es crrónco preguntarse por esta arbitrariedad. Lo correcto es preguntarse por los valores políticos promovidos por los Estados de un sistema federal en comparación con los valores promovidos por un sistema centrahista. La respuesta depende de la función de los Estados, de los valores politicos que promueven y de la posibilidad o necesidad de reformular sus fronteras.

${ }^{17}$ Esta observación implica que un pueblo tiene al menos un derecho cualificado a lirnitar la inmigración. No me ocupo aqu de cuáles pueden ser las cualificaciones de este derecho. 
las partes (como representantes de pueblos libres e iguales) sean representadas como razonablemente situadas, como racionales y en capacidad de decidir según razones apropiadas. Una de las dos condiciones adicionales es que la sociedad política de pueblos democráticos bien ordenados debería ser estable de la manera correcta ${ }^{18}$. Dada la existencia de una sociedad política de tales pueblos, sus miembros tenderán en forma creciente a aceptar sus principios y juicios del mismo modo que llegan a comprender las ideas de justicia expresadas por la ley entre ellos y a apreciar sus beneficios para todos los pueblos liberales.

Decir que la sociedad de los pueblos democráticos es estable de la manera corrccta significa que lo es con respecto a la justicia, esto es, que las instituciones y prácticas entre los pueblos satisfacen siempre los principios relevantes de la justicia, aunque presumiblemente las condiciones sociales siempre cambian. Es decir, además, que el derecho de gentes es respetado no simplemente por un afortunado equilibrio de poder - de suerte que alterarlo va contra los intereses del pueblo-, sino porque, a pesar de las cambiantes posturas de los distintos pueblos, todos se adhicren al derecho común y lo aceptan como justo y benéfico para todos. Ello significa que la justicia de la sociedad de los pueblos democráticos es estable con respecto a la distribución de la fortuna entre ellos. Fortuna no alude aquí al éxito militar de la sociedad o a la carencia de él, sino a otras clases de éxito: su disfrute de libertad política y social, la plenitud y la expresividad de su cultura, el bienestar económico de todos sus ciudadanos.

La experiencia histórica sugiere, al menos en cuanto concierne al principio contra la guerra, que esta condición de estabilidad podría satisfacerse en una sociedad de pueblos democráticos justos. Aunque las sociedades democráticas han estado envueltas en guerras tan a menudo como las no democráticas ${ }^{19}$ y han defendido con vigor sus instituciones desde 1800 , como señala Michael Doyle, las sociedades liberales firmemente establecidas no se han enfrentado entre sí militarmente ${ }^{20}$. $Y$ en gucras en las cuales varios grandes poderes estuvieron involucrados, como las dos guerras mundiales, los Estados democráticos han luchado como aliados, en el mismo bando. En efecto, la ausencia de la guerra entre las democracias es lo más aproximado que conocemos a una ley empírica sobre las relaciones

${ }^{15}$ Véase aThe Domain of the Political and Overlapping Consensus», New York University Law School Review, nüm. 64, 1989, p. 245, sec. VII.

10 Véase Jack S. Levy, «Domestic Politics and War», en Robert Rotberg y Theodore Rabb (eds.), The Origin and Prevention of Major Wars, Cambridge, Cambridge University Press, 1989, p. 87. Levy se refiere a varios estudios historicos que han confirmado la conclusion de Small y Singer en el Jenasalem Joumal of Intemational Relations, núm. 1, 1976, mencionado en la nota (21).

7éase Doyle, «Kant, Liberal Legacies and Foreign Affairs», Philosophy and Pubic Affairs, núm. 12, 1083, pp. 205 y 323. Dice Doyle: «Estas convenciones (basadas en las implicaciones internacionales de los principios y las instituciones liberales) de respcto mutuo han formado un fundamento cooperativo notablemente efectivo para las relaciones entre las democracias liberales. Aunque los Estados liberales han estado involucrados en numerosas guerras con Estados no libcrales, los Estados liberales constitucionalmente seguros no han librado guerra alguna entre sí. Nadie alegaría que tales guerras son imposibles; pero las pruebas preliminares parecen indicar... una significativa predisposición contra la guerra entre los Estados liberalesm. 
entre las sociedades ${ }^{21}$. Si así fuere, supondré que una sociedad de pueblos democráticos, cuyas instituciones fundamentales están bien ordenadas conforme a concepciones liberales de la justicia (aunque no necesariamente por la misma concepción), será estable en el sentido ya definido. El esquema del derecho de tales pueblos, en consecuencia, parece cumplir la condición de realismo político que se deriva de la condición de estabilidad.

Obsérvese que propongo lo que llamo la ley de Doyle como prevaleciente en democracias liberales bien ordenadas y bien establecidas, que sean naciones significativas o grandes potencias. Las razones para la prevalcncia de la ley de Doyle, en el supuesto de que pueda hablarse de ella, son ampliamente compatibles con las democracias reales, caracterizadas como están por grandes injusticias y tendencias oligárquicas, al igual que por su intervención frecuentemente encubierta en países más pequeños cuyas democracias son más inestables e inseguras. Piénsese en los Estados Unidos al derrocar las democracias de Allende en Chile, Arbenz en Guatemala, Mossadegh en Irán e incluso los sandinistas en Nicaragua. Cualesquiera sean los méritos de estos regímenes, las operaciones encubiertas en su contra pueden ser adelantadas por una burocracia gubernamental bajo la presión de intereses oligárquicos sin el conocimiento o la crítica del público, y presentadas luego como hechos consumados. Todo esto resulta tanto más fácil cuanto que la obvia apelación a la seguridad nacional por la rivalidad entre las superpotencias durante la guerra fría permitió que esas democracias aparecieran, de manera harto improbable, como un peligro. Aunque los pueblos democráticos no sean expansionistas, de todos modos defienden su seguridad, lo cual puede ser manipulado muy fácilmente por un gobierno oligárquico en el contexto de la rivalidad entre las superpotencias para justificar sus operaciones encubiertas cuando éstas son desenmascaradas ${ }^{22}$.

La última condición para aceptar como bueno este esquema del derecho de gentes es que, como ciudadanos de sociedades liberales, podamos respaldar de manera reflexiva sus principios y juicios. Debemos estar en capacidad de decir que la doctrina del derecho de gentes, más que cualquier otra, atiende nuestras convicciones políticas y valoraciones morales de todo tipo, de las más generales a las más particulares, en un sistema coherente.

${ }^{2}$ Véase Lery 5 «Domestic Politics», p. 88. En estos estudios, la mayoría de las definiciones de la democracia son comparables a la de Small y Singer scgón Levy: 1) elecciones regulares y participación de los partidos de oposicion; 2) al menos un 10 por 100 de la población adulta habilitada para votar, y 3) un parlamento que controle a la rama ejecutiva o comparta con ella la responsabilidad del Estado. Nuestra definición de democracia liberal va mucho más allá.

22 Vcase Alan Gilbert, «Power-Rivalry Motivated Democracy», Political Theory, núm. 20, 1992; pp. 681 y 684 . 


\section{La extensión a las sociedades jerárquicas}

Recordemos la sección III: la extensión de las ideas liberales de justicia al derecho de gentes procede en dos etapas, cada una con dos pasos. La primera etapa es la de la teoría ideal y acabamos de dar su primer paso: la extensión del derecho de gentes a las sociedades liberales bien ordenadas. El segundo paso de la teoría ideal es más difícil: requiere determinar un segundo tipo de sociedad, jerárquica, como la hemos llamado, y luego declarar cuándo dicha sociedad está bien ordenada. Nuestro propósito es extender el derecho de gentes a estas sociedades jerárquicas bien ordenadas y mostrar que ellas aceptan el mismo derecho de gentes que las sociedades liberales. Este derecho compartido de los pueblos bien ordenados, tanto liberales como jerárquicos, determina el contenido de la teoría ideal. Especifica la clase de sociedad de pueblos bien ordenados que todas las gentes querrian y fija la finalidad regulativa de su política exterior. Lo que es más importante para nosotros, entraña el obvio corolario de que las sociedades no liberales también respetan los derechos humanos.

Procedemos entonces en esta dirección. Primero, formulamos tres requisitos de cualquier régimen jerárquico bien ordenado. Es claro que cumplir estos requisitos no convierte en liberal a dicho régimen.

Segundo, confirmamos que, en una posición original con un velo de ignorancia, los representantes de regímenes jerárquicos bien ordenados se encuentran razonablemente situados, son racionales y están motivados por razones apropiadas. También en este caso, la posición original es un mecanismo de representación para la adopción del derecho entre pueblos jerárquicos. Tercero, mostramos que en la posición original los representantes de sociedades jerárquicas bien ordenadas adoptarían el mismo derecho de gentes que los representantes de sociedades liberales. Ese derecho sirve entonces como derecho común de una sociedad política justa de pueblos bien ordenados.

El primero de los tres requisitos para que una sociedad jerárquica esté bien ordenadas es que sea pacífica y persiga sus fines legítimos a través de la diplomacia, el comercio y otros medios pacíficos. De aquí se deduce que su doctrina religiosa, que se supone ser comprehensiva e influyente en la política gubernamental, no es expansionista, pues respeta por completo el orden cívico y la integridad de las otras sociedades. Si se propone alcanzar mayor influencia, lo hace de manera que resulte compatible con la independencia y las libertades de las otras sociedades. Este rasgo de su religión sustenta el fundamento institucional de su conducta pacífica y la distingue de los principales Estados europeos durante las guerras religiosas de los siglos xvi y xvir.

Un segundo requisito fundamental se sirve de una idea de Philip Soper que tiene varias partes. Requiere, primero, que el sistema jurídico de una sociedad jerárquica imponga deberes y obligaciones morales a todas las personas dentro 
de su territorio ${ }^{23}$. Requiere, además, que su sistema jurídico esté orientado por una concepción de justicia basada en el bien común, lo cual significa que tiene en cuenta de manera imparcial y razonable los intereses fundamentales de todos los miembros de la sociedad. No se trata de que los intereses de algunos sean arbitrariamente privilegiados mientras los de otros no reciben atención. Por fin, los jueces y administradores del orden jurídico deben creer sincera y razonablemente que el derecho está bajo la orientación efectiva de una concepción de la justicia basada en el bien común. Esta creencia ha de ser demostrada por una disponibilidad a defender públicamente las decisiones estatales justificadas por la ley. Los tribunales constituyen una eficiente manera de lograr tal objetivo ${ }^{24}$. Estos aspectos del orden juridico son necesarios para establecer la legitimidad del régimen a los ojos de su propio pueblo. Para resumir el segundo requisito podemos decir que existe la creencia sincera y razonable de que el sistema jurídico está orientado por una concepción de la justicia basada en el bien común, tiene en cuenta los intereses esenciales del pueblo e impone deberes y obligaciones morales a todos los miembros de la sociedad.

Puede añadirse para abundar que este segundo requisito implica que las instituciones políticas de una sociedad jerárquica bien ordenada constituyen una razonable jerarquía consultiva. Ellas incluyen una familia de cuerpos representantivos u otras asambleas cuya tarea consiste en velar por los intereses relevantes de todos los elementos de la sociedad. Aunque en las sociedades jerárquicas las personas no son tenidas como ciudadanos libres e iguales, lo cual sí ocurre en las sociedades liberales, son consideradas como miembros responsables de la sociedad, que pueden reconocer sus deberes y obligaciones morales y jugar su papel en la vida social.

Frente a una jerarquía consultiva existe la oportunidad de escuchar varias voces, no en la forma permitida por las actuaciones democráticas, pero sí de manera apropiada, a la luz de los valores religiosos y filosóficos de la sociedad en cuestión.

25 Aqui me inspiro en Philip Soper, A Theoy of Law, Cambridge, Harvard University Press, 1984, pp. 125-147. Soper mantiene que un sistcma juridico, que no es lo mismo que un sistema de simples órdencs coactivamente aplicadas, ha de ser tal que en él se impongan deberes y obligaciones mnrales a todos los miembros de la sociedad, y que los jueces y otros funcionarios deben creer sincora y razonablemente que el derecho está orientado por una concepción de la justicia basada en el bjen común. El contenido de dicha concepción implica la imposición de obligaciones moralmente vinculantes sobre todos los integrantes de la socicdad. Menciono algunos detalles de la teoria de Soper pero de manera informal, sin intención de explicar su pensamicnto. Como muestra el texto, mí propósito es presentar una concepción de la justicia que si bien no es liberal, contiene clementos que dan a las sociedades reguladas por ella el templo moral requerido para convertirse en miembros de una socicdad política gobernada por un razonable derecho de gentes. Sin embargo, conviene entender este segundo requisito con cuidado. Para Sopet, es parte de la definición de un sistema jurídico. Se trata de una exigencia que todo esquema de reglas dche cumplir para ser un sistema juridico propiamente dicho. Vcase cap. 4, pp. 91-100. No sigo a Soper en este punto ni lo rechazo, pues sus argumentos son fuertes. Más bien lo hago a un lado para adoptar como requisito an principio moral sustantivo, explicable como partc de un derecho de gentes que surja de una concepción liberal de la justicia. Con elío se cvita el prolongado debate de la filosofia jurídica en torno a la definición del derecho. Tampoco quiero alegar que antes de la guerra civil norteamericana el Sur no tenía un sistema jurídico. Expreso mi reconocimiento a Samuel Freeman por nuestras valiosas discusiones sobre cstos temas.

to Soper, A Theory of Law, pp. 112 y 118. 
Así, los individuos no tienen la libertad de expresión como en una sociedad liberal; pero en tanto miembros de asociaciones y organismos tienen el derecho de expresar su disentimiento político en cierto punto del proceso consultivo y el gobierno tiene la obligación de tomar su disenso en serio y responder a él de manera consciente. Es necesario que sean oídas distintas voces porque la convicción sincera de los jueces y otros funcionarios se compone de dos elementos: honestidad y respeto por la posibilidad del disentimiento ${ }^{25}$. Unos y otros deben estar dispuestos a responder a las objeciones. No pueden rehusarse a escucharlas con el argumento de que quienes las expresan son incompetentes y no entienden. Si así fuese, no tendríamos una jerarquía consultiva, sino un régimen puramente paternalista.

Ante csta versión del fundamento institucional de una sociedad jerárquica, podemos decir que su concepción de la justicia basada en el bien común asegura al menos que todas las personas tengan ciertos derechos mínimos: a los medios de subsistencia y seguridad (derecho a la vida) ${ }^{26}$; a la libertad frente a la esclavitud, la servidumbre y la ocupación armada; a la propiedad personal y a la igualdad formal expresada en las reglas de la justicia natural ${ }^{27}$ (por ejemplo, el tratamiento igual de casos iguales). Ello demuestra que una sociedad jerárquica bien ordenada también cumple un tercer requisito: respeta los derechos humanos fundamentales.

Esta conclusión se basa en que el segundo requisito excluye las violaciones de los derechos humanos. Pues el orden jurídico de la sociedad ha de imponer deberes y obligaciones morales a todas las personas en su territorio y establecer una razonable jerarquía consultiva que proteja los derechos humanos. El mismo resultado se obtiene cuando existen jueces y funcionarios sincera y razonablemente persuadidos de que el sistema jurídico está orientado por una concepción de la justicia basada en el bien común. Tal convicción no sería razonable ni racional si esos derechos son quebrantados.

Conviene hacer una referencia explícita al problema de la tolerancia religiosa. Mientras que en las sociedades jerárquicas una religión de Estado puede ser en algunas materias la autoridad suprema de la sociedad y controlar la política gubernamental en ciertos asuntos importantes, esa autoridad no se extiende políticamente a otras sociedades. Más aún, sus doctrinas comprehensivas religiosas o filosóficas no carecen de razonabilidad: admiten una cjerta cantidad de libertad de conciencia y de pensamiento, incluso si tal libertad no es igual para todos los miembros de la sociedad, como ocurre en los regímenes liberales ${ }^{28}$. Una sociedad jerárquica

\footnotetext{
${ }^{25}$ Ibidem, p. 141.

${ }^{*}$ Henry Shue, Baric Rights: Substance, Afuence and US Foreign Policy, Princepton, Princeton University Press, 1980, p. 23. Shue y Vincent en su Human Rights consideran que la subsistcncia incluye cierta seguridad económica mínirna y que los derechos de subsistencia son fundamentales. Este punto de vista puede compartirse, puesto que el ejercicio razonable y racional de todas las libertades, así como el empleo inteligente de la propiedad, implica siempre la posesión de ciertos medios económicos de uso universal.

${ }^{27}$ Sobre las reglas de la justicia natural, veáse H. L. A. Hart, The Concept of Law, Oxford, Clarendon Press, 1961, p. 156.

${ }^{2}$ Podria plantearse la siguicnte cuestión: ¿Por qué no son irrazonables las doctrinas religiosas o filosóficas que niegan la libertad absoluta de conciencia? No he dicho, empero, que sean razonables, sino más bien que no son irrazonables. Pienso que debería existir una distancia entre lo razonable,
} 
puede tener una religión institucionalizada con ciertos privilegios. Para ser bien ordenada, sin embargo, es esencial que ninguna religión sea perseguida o que le sean negadas las condiciones cívicas y sociales que permitan su práctica pacífica y libre de intimidación ${ }^{29}$. Debido a la inequidad de la libertad religiosa, si no por otra razón, también es esencial que una sociedad jerárquica reconozca el derecho a emigrar ${ }^{30}$. Los derechos mencionados se incluyen entre los fundamentales. En la sección $V$ volveremos sobre su papel y estatuto.

Un fundamento institucional que cumpla los tres requisitos puede asumir muchas formas. Esto merece subrayarse, puesto que he indicado tan sólo el caso de la religión. No tratamos de describir todas las formas posibles de orden social que corresponden a una razonable sociedad de naciones. Hemos especificado más bien las tres condiciones necesarias para pertenecer a una razonable sociedad de naciones y hemos mostrado con ejemplos que tales condiciones no requieren que la sociedad sea liberal.

Así concluye la presentación de los requisitos para las instituciones básicas de una sociedad jerárquica bien ordenada. Mi objetivo ha sido plantear una concepción de la justicia que, si bien distante de las concepciones liberales, todavía tenga características que confieran a las sociedades así reguladas el estatuto moral exigido para pertenecer de buena fe a una razonable sociedad de pueblos bien ordenados. Conviene advertir, como he observado atrás, que un acuerdo en torno a un derecho de gentes que garantice los derechos humanos no puede ser concluido tan sólo por sociedades liberales. Debemos confirmarlo a continuación.

Las sociedades jerárquicas están bien ordenadas de conformidad con sus propias concepciones de la justicia ${ }^{31}$. Así, en una posición original adecuada sus representantes adoptarían los mismos principios planteados que acogerían los representantes de las sociedades liberales.

Los intereses de cada sociedad jerárquica son interpretados por sus representantes de acuerdo con su concepción de la justicia. Ello nos permite afirmar que también en este caso la posición original es un mecanismo de representación.

Dos consideraciones confirman lo anterior. La primera es que, a la luz de la concepción de la justicia basada en el bien común de una sociedad jerárquica, las partes se preocupan por el bien de la sociedad que representan, al igual que por su seguridad en tanto se encuentre garantizada por las leyes contra la guerra y la agresión. Se preocupan también por los beneficios del comercio y de la asistencia entre los pueblos en tiempos de necesidad. Todo esto contribuye a proteger los derechos humanos. Por ello, podemos decir que los representantes de las sociedades

que demanda la completa libertad de concicncia, y lo irrazonable, que la niega por entero. Las doctrinas tradicionales, que permitcn una limitada libertad de conciencia, caen dentro de este espacio y no son irrazonables. Véase al respecto mi Political Liberalism, Conferencia II, sección 3.

${ }^{29}$ Sobre la importancia de esto, veáse Judith Shklar, Ordinary Vices, Cambridge, Harvard University Press, 1984, caps. 1 y 6 , donde se presenta lo que se llama el liberalismo del miedo o el liberalismo de las minorias permanentes. De la misma autora veáse Legalism, Cambridge, Harvard University Press, 1963, p. 224.

3) Con ciertas cualificaciones, las sociedades liberales también deben permitir este derecho.

${ }^{31}$ Que no son las concepciones políticas de la justicia de las que yo hablo. Véase la nota 2. 
jerárquicas son racionales. La segunda consideración es que las partes no tratan de extender sus doctrinas religiosas y filosóficas a otros pueblos mediante la guerra o la agresión, y respetan el orden cívico y la integridad de otras sociedades. En consecuencia, aceptan - como usted y yo lo haríamos - ${ }^{32}$ la posición original como justa entre los pueblos, y se adheririan al derecho de gentes adoptado por sus representantes, en tanto establece términos justos de cooperación política entre ellos y otras sociedades. Así, los representantes están razonablemente situados y esto es suficiente para el empleo de la posición original como un mecanismo de representación para extender el derecho de gentes a las sociedades jerárquicas ${ }^{33}$.

Nótese que he supuesto que las partes como representantes de pueblos están igualmente situadas, aun cuando la concepción de justicia de la sociedad jerárquica por cllos representada permite algunas desigualdades básicas entre sus miembros. Por ejemplo, algunos no disfrutan de igual libertad de conciencia. No existe, sin embargo, inconsistencia en ello: un pueblo que afirma sinceramente una concepción no liberal de la justicia puede creer todavía que su sociedad debería ser tratada de manera igualitaria en un justo derecho de gentes, aunque sus miembros acepten desigualdades básicas entre sí. Aunque una sociedad carezca de igualdad fundamental, es razonable para ella asistir en la igualdad al formular sus reivindicaciones contra otras sociedades.

Dos observaciones sobre este último punto. Una es que, si bien la posición original en el primer nivel, el de la justicia doméstica, incorpora una concepción política de la persona arraigada en la cultura pública de una sociedad liberal, no sucede lo mismo con la posición original en el segundo nivel, el del derecho de gentes. Subrayo este hecho que permite a una concepción liberal de la justicia extenderse para sustentar un derecho de gentes más general sin prejuzgar en contra de sociedades no liberales.

Esto conduce a una segunda observación. Como se mencionó antes, el derecho de gentes podía haber sido formulado a partir de una posición original omnicomprensiva con representantes de todos los individuos del mundo ${ }^{34}$. En este caso, la cuestión de si debe haber sociedades separadas y de las relaciones entre ellas será acordada por las partes tras un velo de ignorancia. A simple vista, no aparece claro por qué proceder de este modo debería llevarnos a resultados diferentes que, como lo he hecho, proceder a partir de sociedades separadas hacia afuera. Con todo, se debe alcanzar el mismo derecho de gentes en ambos casos. La dificultad de una posición omnicomprensiva o global estriba en que su empleo de las ideas liberales es mucho más problemático, pues en este caso tratamos a todas las personas, con prescindencia de sus sociedad y cultura, como individuos libres e iguales, razo-

32 Aquí «usted y yoo somos miembros de sociedades jerárquicas, pero una vez más, no de la misma.

${ }^{3}$ Aqu ́ estoy en deuda con Lea Brilmayer, de la Universidad de New York, por haber scñalado que en mi esquema del derecho de gentes en octubre de 1990 no se planteaban estas condiciones en forma satisfactoria.

* Brian Barry, en su espléndido libro Theories of Justice, Berkeley, University of California Press, 1989, pp. 183-189, discute el mérito de esta tarea y levanta serias objeciones a lo que considera mi visión de los principios de justicia distributiva para el derecho de gentes. No discuto aquí sus importantes criticas, pero menciono en adelante preguntas con ellas relacionadas. 
nables y racionales, de acuerdo con una concepción liberal. Ello hace del derecho de gentes un fundamento muy estrecho.

En consecuencia, pienso que es mejor seguir el procedimiento de abajo hacia arriba en dos niveles ${ }^{35}$, empezando primero con los principios de justicia para la estructura básica de la sociedad doméstica y ascendiendo luego al derecho de gentes. Así, nuestro conocimiento sobre el comportamiento histórico de los pueblos y sus gobiernos nos orienta sobre cómo proceder y sugiere preguntas y posibilidades que de otra manera se nos escaparían. Pero éste es simplemente un punto metodológico que no resuelve cuestiones sustanciales, las cuales dependen de lo que puede ser efectivamente conseguirlo.

Se puede ser escéptico acerca de la posibilidad de que un contrato social liberal $y$ una idea constructivista ${ }^{36}$ de la justicia alcancen una formulación tal que una concepción del derecho de gentes tenga alcance universal y se aplique también a sociedades no liberales. Nuestra discusión sobre las sociedades jerárquicas debería despejar estas dudas. He subrayado las condiciones bajo las cuales podríamos aceptar como sensato y justificado el derecho liberal de gentes que hemos esbozado. A este respecto, considerábamos si tal derecho era estable en materia de justicia y si de manera reflexiva podíamos aceptar los juicios a que sus principios y preceptos nos conducían. Si ambas cosas se sostienen, decíamos, el derecho de gentes podía, según los criterios que podemos aplicar ahora, ser aceptado como justificado.

Observaciones comparables caben sobre un derecho de gentes más amplio, que incluya a las sociedades jerárquicas bien ordenadas. Aquí agrego simplemente, sin argumentos ni pruebas pero con la esperanza de que parezca plausible, que estas sociedades respetarán un justo derecho de gentes por las mismas razones que los pueblos liberales, y que unos y otros hallaremos aceptables para nuestras convicciones los juicios a que aquél conduce. Considero importante que las sociedades jerárquicas bien ordenadas sean no expansionistas y que su ordenamiento jurídico esté oricntado por una concepción de la justicia basada en el bien común, que garantice su respeto de los derechos humanos. Estas sociedades sostienen igualmente una pacífica sociedad de los pueblos y se benefician de ella como las sociedades liberales. Todas ticnen un interés común en cambiar la manera en la cual la política entre los pueblos - la guerra y las amenazas de guerra - ha sido manejada hasta hoy.

Podemos entonces calificar como sensato y justificado este más amplio derecho de gentes. Este aspecto fundamental merece subrayarse: no hay ninguna diferencia relevante entre la justicia como equidad para el caso doméstico en Una Teoria de la Justicia y el derecho de gentes basado en ideas liberales más generales sobre

" Podemos ayanzar hacia la tercera ctapa y hacia etapas posteriores al ponsar en grupos de socicdades unidas en asociaciones regionales o federaciones de algún tipo, como ta Comunidad Furopea o la Comunidad de Repúblicas de la antigua Unión Soviética. Es natural vislumbrar la sociedad mundial del futuro como una combinación de tales federaciones y de ciertas instituciones como las Naciones Unidas, capaces de hablar por todas las sociedades del mundo.

* Una idea tal es la justicia como equidad. Para nuesiros propósitos, otras idcas liberales más generales sobre la justicia encajan en la misma descripción. Y ello no se afecta porque carezcan de los tres elementos igualitarios de la justicia como equidad que se mencionan en el primer párrafo de la sección III. 
la justicia. En ambos casos usamos la misma idea básica de un procedimiento razonable de construcción, en el cual los agentes racionales equitativamente situados (las partes como representantes de los ciudadanos en un caso y de los pueblos o las sociedades en el otro) seleccionan principios de justicia según el sujeto relevante, sus instituciones domésticas separadas o el derecho de gentes que comparten. Como siempre, las partes se guían por las razones apropiadas que se especifican por un velo de ignorancia. Así, las obligaciones no son impuestas por una sociedad a otra; en su lugar, las sociedades razonables acuerdan cuáles serán los lazos entre ellas. Una vez confirmemos que una sociedad doméstica o una sociedad de los pueblos, regulada por los respectivos principios de justicia, es estable en materia de justicia (como se definió previamente) y verifiquemos que podemos suscribir de manera reflexiva esos principios, entonces en ambos dominios se justificarán de igual modo los ideales, las leyes y los principios de la justicia ${ }^{37}$.

\section{Derechos humanos}

Las principales características de los derechos humanos se presentan a continuación. Primero, estos derechos no dependen de ninguna doctrina moral comprehensiva o concepción filosófica de la naturaleza humana según la cual, por ejemplo, todos los seres humanos son personas morales y tienen igual dignidad u ostentan ciertos poderes morales e intelectuales particulares que los invisten de esos derechos. Esto requeriría una muy profunda teoría filosófica que muchas, si no todas, de las sociedades jerárquicas podrán rechazar como liberal o democrática o, en alguna forma, característica de la tradición política occidental y, por tanto, discriminatoria frente a otras culturas.

Adoptamos, por consiguiente, un enfoque diferente: los derechos humanos fundamentales expresan un patrón mínimo de instituciones políticas bien ordenadas para todos los pueblos que pertenecen, como miembros de buena fe, a una justa sociedad política de los pueblos ${ }^{38}$. Cualquier violación sistemática de tales derechos es una falta grave que afecta a la sociedad de los pueblos todos, liberales y jerár-

${ }^{37}$ Existen, sin embargo, algunas diferencias. Los tres requisitos de legitimidad que se discuten en esta sección deben ser tenidos como condiciones necesarias para que una sociedad sea miembro de buena fe de una razonable sociedad de los pueblos, y muchas doctrinas religiosas y filosóficas con diferentes concepciones de la justicia bien pueden conducir a instituciones que satisfagan estas condiciones. A] definir un razonable derecho de gentes, las sociedades con tales instituciones se consideran bien ordenadas. Pero dichos requisitos no especifican una concepción politica de la justicia en el sentido que yo le doy [veáse la nota 2]. Supongo que la concepción de la justicia basada en el bien común de una sociedad es considerada como una parte de su doctrina comprehensiva religiosa o filosófica. No he sugerido que tal concepción sea constructivista y asumo que no lo es. Cosa distinta es si los tres requisitos de legitimidad pueden ser formulados dentro de una perspectiva de contrato social. Dejo la cuestión abierta. Pero ninguna de estas diferencias afecta mi pretensión, según la cual en ambos dominios los ideales y principios de la justicia están justificados de la misma manera.

* Aquí me inspiro en la instructiva discusiơn de T. M. Scanlon, "Human Rights as a Neutral Concernw, en P. Brown y D. MacLean (eds.), Human Rights and US Foreign Policy, Lexington, Lexington Books, 1979. 
quicos. Puesto que ellos expresan unos parámetros mínimos, sus requisitos deberían ser muy débiles.

Recuérdese que hemos postulado que el sistema jurídico de una sociedad debe imponer deberes y obligaciones morales a todos sus miembros, y ha de ser regulado por lo que los jueces y otros funcionarios creen sincera y razonablemente que es una concepción de la justicia basada en el bien común. Para que esta condición se sostenga, la ley debe reconocer al menos aquellos derechos básicos como el derecho a la vida y a la seguridad, el derecho a la propiedad personal y los elementos del debido proceso, al igual que el derecho a la libertad de conciencia, el derecho de asociación y el derecho a emigrar. Estos son los derechos humanos.

A continuación, consideramos lo que implica la imposición de tales deberes y obligaciones: una concepción de la justicia basada en el bien común y la buena fe de los funcionarios, al explicar y justificar el orden legal a quienes están sujetos a él. No se requiere la idea liberal según la cual las personas son ante todo ciudadanos y, como tales, miembros libres e igualcs de la sociedad, que sostiene estos derechos como fundamentales para los ciudadanos. Se requiere más bien que las personas sean miembros activos y responsables de la sociedad, y que puedan reconocer sus deberes y obligaciones morales, y actuar en consecuencia. Sería difícil rechazar estas exigencias (una concepción de la justicia basada en el bien común y una justificación oficial de la ley basada en la buena fe) como exorbitantes para un régimen mínimamente decente. Entendidos como resultado de estos requisitos, los derechos humanos no podrían ser rechazados por ser liberales o especiales en nuestra tradición occidental. En tal sentido, son políticamente neutrales ${ }^{39}$.

Para confirmar este último punto, considero una aparente dificultad. Muchas sociedades tienen tradiciones políticas diferentes del individualismo occidental en sus múltiples modalidades. Al considerar a las personas desde una perspectiva política, se dice que estas tradiciones las ven no como ciudadanos con sus derechos, sino más bien como miembros de grupos: comunidades, asociaciones o corporaciones ${ }^{40}$. En esta visión alternativa, de signo asociacionista, cualquier derecho que tenga la persona proviene de esta adscripción originaria y es normalmente un derecho de habilitación, que capacita a la persona para desempeñar sus deberes en los grupos a los cuales pertenece. Con respecto a los derechos políticos, el punto se puede ilustrar con el rechazo de Hegel a la idea de aun hombre, un voto», por cuanto ella expresaría la noción democrática e individualista de que cada persona, como un átomo, tiene el derecho fundamental a participar en igualdad de condiciones en la deliberación política ${ }^{41}$. En contraste, de acuerdo con La Filosofia del Derecho de Hegel, en el Estado racional bien ordenado las personas pertenecen en primer lugar a haciendas, corporaciones y asociaciones. Puesto que

\$9 Scanlon subraya este punto en «Human Rights», pp. 83 y 89-92, el cual resultará relevante cuando en las secciones VI y VII obscrvemos que el respeto de los derechos humanos debe ser parte de la politica exterior de las sociedades bien ordenadas.

an Véase R. J. Vincent, «The Idea of Rights in International Ethies», en Terry Nardin y David Mapel (eds.), Traditions of Mnemational Ethics, Cambridge, Cambridge University Press, pp. 262-265.

${ }^{4}$ G. W. Hegel, Ia Filosofia del Derecho, 1821, sección 308. 
estas formas sociales representan los intereses racionales ${ }^{42}$ de sus miembros en lo que Hegel considera una justa jerarquía consultiva, algunas personas actuarán políticamente como representantes de tales intereses en el proceso de consultas, pero lo harán como miembros de corporaciones y no como individuos, y no todos los individuos están vinculados al proceso.

El punto esencial es que los derechos humanos fundamentales, como lo hemos descrito, pueden ser protegidos en un Estado jerárquico bien ordenado con su jerarquía consultiva; lo que es válido en el esquema hegeliano para los derechos políticos, lo es también para todos los derechos ${ }^{43}$. Su sistema jurídico puede realizar las condiciones propuestas y garantizar el derecho a la vida y a la seguridad, el derecho a la propiedad personal y a los elementos del debido proceso, el derecho a la libertad de conciencia y el derecho de asociación. Dichos derechos son reconocidos a las personas como miembros de gremios y corporaciones, y no como ciudadanos. Pero no importa. Los derechos se reconocen, y se cumple el requisito de que un sistema legal debe imponer deberes y obligaciones morales. Vistos a la luz de esa condición, los derechos humanos no pueden ser rechazados como peculiares de nuestra tradición occidental.

Los derechos humanos son una categoría especial de derechos, diseñada para jugar un papel especial en un razonable derecho de gentes para la época presente. Recuérdese que las ideas adquiridas sobre derecho internacional cambiaron en dos sentidos básicos después de la Segunda Guerra Mundial, y este cambio en las creencias morales básicas es comparable a otros cambios históricos profundos ${ }^{44}$. La guerra ya no es un medio aceptable de política estatal. Se justifica tan sólo en legítima defensa, y la soberanía interna del Estado se encuentra limitada hoy. Una de las funciones de los derechos humanos es precisamente fijar los límites de esa soberanía.

Los derechos humanos difieren entonces de los derechos constitucionales o de los derechos de la ciudadanía democrática ${ }^{45}$ o de otras clases de derechos pertenccientes a ciertos tipos de instituciones políticas, tanto individualistas cuanto asociacionistas. Constituyen una categoría especial de derechos de aplicación universal, difícilmente controvertibles en su intención general. Son parte de un razonable derecho de gentes y fijan límites a las actuaciones domésticas exigidas por ese derecho a todos los pueblos. En este sentido, establecen la última frontera

4: El significado de «racional» $\mathrm{cs}$ aquí muy próximo a «razonable», El vucablo alemán es vernünfig, que tiene toda la fuerza de la razón en la tradición filosófica alemana, lejos del significado económico de racional, a traducir por zweckmässig o rationell.

${ }^{43}$ Existe una complicación en la concepción hegeliana de ciertos derechos como puramente individuales. Para Hegel, los derechos a la vida, a la seguridad y a la propiedad personal están cimentados en la personalidad, y la libertad de conciencia se deriva de la condición de sujeto moral subjetivamente libre. Agradezco a Frederick Newhouser nuestra discusion al respecto.

4 Véase Keith Thomas, Man and the Natural World, New York, Pantheon Books, 1983, para un examen de la historia de las cambiantes actitudes hacia los animales y la naturaleza.

45 Véase la exclarecedora discusión de Judith Shklar, American Citizenship, Cambridge, Harvard University Press, 1991, con su énfasis en el significado histórico de la esclavitud. 
del derecho doméstico admisible en sociedades integrantes de buena fe de una justa sociedad de los pueblos ${ }^{46}$.

Los derechos humanos tienen estas tres funciones:

1. Son una condición necesaria de la legitimidad del régimen y de la decencia de su orden jurídico.

2. Cuando operan en debida forma, resultan suficientes para excluir la justificada intervención de otros pueblos mediante sanciones cconómicas o, en casos graves, la fuerza militar; $y$

3. Fijan un límite al pluralismo entre los pueblos ${ }^{47}$.

\section{La teoria no ideal: la inobservancia}

Hasta ahora hemos estado ocupados solamente de la teoría ideal. En desarrollo de una concepción liberal de la justicia, hemos revisado los fundamentos filosóficos y morales de una concepción ideal de una sociedad de pueblos bien ordenados, y de los principios aplicables a su normatividad y a sus prácticas. Esa concepción ha de guiar la conducta reciproca de los pueblos y la construcción de instituciones comunes para su beneficio.

Para completar nuestro esquema del derecho de gentes, empero, debemos tomar nota, aun cuando no podemos discutirlas de manera apropiada, de las cuestiones que surgen de las condiciones no ideales de nuestro mundo, con sus grandes injusticias y sus extendidos males sociales. La teoría no ideal se pregunta cómo puede ser alcanzada la concepción ideal de la sociedad de pueblos bien ordenados $o$, al menos, cómo puede avanzarse hacia ella de modo gradual. Busca políticas y cursos de acción que sean efectivos, al igual que políticamente posibles y moralmente permisibles, para tal fin. En estos términos, la teoría no ideal presupone que la teoría ideal ya está disponible, pues hasta tanto no se identifique el ideal, al menos en líneas generales, la teoría no ideal carece de un objetivo con referencia al cual sus preguntas puedan ser respondidas. $Y$ si bien las condiciones especificas de nuestro mundo en un momento dado - el statu quo- no determinan la concepción ideal de la sociedad de los pueblos bien ordenados, esas condiciones sí afectan las respuestas a las preguntas de la teoría no ideal. Se trata de preguntas

* Fste hecho acerca de los derechos humanos puede ser aclarado mediante la distinción entre las diferentes clases de derechos en las diferentes declaraciones intenacionales. Considérese la Declaración Universal de 1948, cuyos artículos 3 y 5 reconocen derechos humanos propiamente dichos. Los derechos consagrados en los artículos 3 a 18 pueden caer bajo esta denoninación si se resuelven ciertas cuestiones de interpretación. Luego están los derechos que son derivaciones obvias de los primeros, como los casos extremos recogidos en las Convenciones sobre genocidio y apartheid de 1948 y 1973 . Estas dos categorias comprenden los derechos humanos.

Otras garantias parecen más bien aspiraciones liberales, como las del artículo primero de la Declaración Universal sobre la dignidad humana, o presuponen tipos específicos de instituciones, como los artículos 22 y 23 del mismo instrumento, sobre seguridad social y salario igual.

${ }^{47}$ Vease Nardin, Law, Morality and the Relations of States, p. 24, que cita a Luban, «The Romance of the Nation-Statew, p. 396. 
de transición: en cualquier caso, parten de la situación en que se encuentra una sociedad y buscan medios efectivos conforme al derecho de gentes para que la sociedad avance cierto trecho hacia su meta.

Podcmos distinguir dos clases de teoría no ideal. La una tiene que ver con las condiciones de inobservancia, esto es, las condiciones en las cuales ciertos regímenes se niegan a reconocer un razonable derecho de gentes. A estos regímenes podemos llamarlos proscritos. La otra clase se refiere a las condiciones desfavorables, es decir, las condiciones de los pueblos cuyas circunstancias históricas, sociales y económicas dificultan o imposibilitan el logro de un régimen liberal o jerárquico bien ordenado.

Empiezo con la teoría de la inobservancia. Como hemos dicho, un razonable derecho de gentes orienta a los regímenes bien ordenados para que hagan frente a los regímenes proscritos, al precisar la meta que siempre deberían tener en mente e indicar los medios que pueden usar o tienen que evitar en la búsqueda de esa meta.

Los regímenes proscritos forman un grupo variopinto. Algunos están encabezados por gobiernos que no parecen reconocer ninguna concepción del derecho y la justicia; con frecucncia, su ordenamiento jurídico es en el fondo un sistema de opresión y terror. El régimen nazi constituye un ejemplo demoníaco de ello. Un caso más común, filosóficamente más interesante e históricamente más respetable, es el de aquellas sociedades que rechazarían el apelativo de regímenes proscritos y cuyos gobernantes sostienen doctrinas comprensivas que no reconocen límites a la legítima autoridad de sus postulados religiosos o filosóficos. España, Francia y la dinastía de los Habsburgo intentaron en algún momento someter a Europa y al mundo a su voluntad ${ }^{48}$. Esperaban difundir la verdadera religión y la cultura, y buscaban la dominación y la gloria, para no mencionar la riqueza y el territorio. Tales sociedades sólo pueden ser controladas por un equilibrio de poderes, pero como éste resulta cambiante e inestable, la llamada teoría hegemónica de la guerra viene muy a propósito ${ }^{49}$.

Las sociedades respetuosas de la ley, tanto libres como jerárquicas, en el mejor de los casos pueden establecer un modus vivendi con los regímenes proscritos expansionistas y defender su integridad como lo permite el derecho de gentes. En esta situación, las sociedades respetuosas de la ley conviven con los regímenes proscritos, en un estado de naturaleza, y tienen un deber con su bienestar y el de las demás sociedades, incluso con el de los pueblos sometidos a los regímenes proscritos, pero no con el de sus gobernantes y elites. Estos deberes no son todos igualmente imperiosos, pero existe siempre una obligación de tener en cuenta los objetivos a más largo plazo y de afirmarlos como orientaciones fundamentales de la política exterior. Así, el único fundamento legítimo del derecho a la guerra contra los regímenes proscritos es la defensa de la sociedad de los pueblos bien ordenados $\mathrm{y}$, en casos graves, de las personas inocentes y de sus derechos humanos frente a aquellos regímenes. Esto corresponde a la idea de Kant según la cual nuestro

\footnotetext{
* Véase Ludwig Dehio, The Precarious Balance, New York, Knopf, 1962.

* Robert Gilpin, kThe Theory of Hegemonic Wars, en Rotberg y Rabb (eds.), The Origin and Prevention of Major Wars.
} 
primer deber político es abandonar el estado de naturaleza y someternos todos al imperio de un derecho razonable y justo ${ }^{50}$.

La defensa de los pueblos bien ordenados es apenas la primera y más urgente de las tareas. Otro objetivo a largo plazo, que viene definido por el derecho de gentes, es conseguir que eventualmente todas las sociedades respeten ese derecho, se conviertan en miembros plenos y autosuficientes de la sociedad de los pueblos bien ordenados y garanticen los derechos humanos por doquier. Cómo conseguirlo es un problema de política exterior que exige sabiduría política y que en gran parte depende de la suerte. Se trata de asuntos sobre los cuales la filosofía política no tiene mucho que decir, pero me aventuraré a hacer varias observaciones que resultarán familiares.

Para alcanzar este objetivo a largo plazo, los pueblos bien ordenados deberian establecer nuevas instituciones y prácticas, que sirvan como una especie de centro federativo y foro público de sus opiniones y políticas comunes hacia los demás regímenes. Esto puede acometerse por separado o dentro de instituciones como las Naciones Unidas mediante una alianza de pueblos bien ordenados para ciertos asuntos. Este centro federativo puede ser utilizado para formular y para expresar la opinión de las sociedades bien ordenadas. Allí pueden exponer a la luz pública las crueles e injustas instituciones de los regímenes opresivos y expansionistas, y sus violaciones de los derechos humanos. Incluso estos regímenes no son del todo indiferentes a esta clase de crítica, espccialmente cuando se basa en un razonable y bien fundamentado derecho de gentes que no puede ser desconceptuado con facilidad como liberal u occidental. Gradualmente, los pueblos bien ordenados pueden presionar a los regímenes proscritos para que cambien sus prácticas, pero en sí misma esta presión no parece muy efectiva. Debe ser acompañada por la firme denegación de toda ayuda militar o asistencia económica y de cualquier otro tipo, y los regímenes proscritos no deberian ser admitidos por los pucblos bien ordenados como miembros de buena fe de las instituciones y prácticas de cooperación internacional.

\section{La teoría no ideal: condiciones desfavorables}

Digamos unas pocas palabras sobre la segunda clase de teoría no ideal, la de las condiciones desfavorables. Se trata de las condiciones de sociedades que carecen de las tradiciones políticas y culturales, el capital humano, la tecnologia y los recursos materiales para hacer posible la sociedad bien ordenada. En la teoría de la inobservancia vimos cómo la meta de las sociedades bien ordenadas es en cierto modo traer los Estados proscritos al seno de la sociedad de pueblos bien ordenados. En los casos históricos mencionados, las sociedades proscritas no estuvieron afectadas por la carencia de recursos materiales y tecnológicos o de capital humano; por el contrario, eran las sociedades más avanzadas en lo político y social y más desarrolladas en lo económico en su época. La falla en estas sociedades radica

\footnotetext{
* Véase I. Kant, Filnsofia det Derecho, secciones 44 y 61 .
} 
cn sus tradiciones políticas e instituciones básicas en materia de derecho, propiedad y estructura de clases, junto con su cultura y sus creencias. Estas realidades han de cambiar antes que un razonable derecho de gentes pueda ser aceptado y establecido.

Debemos hacer la pregunta paralela: ¿Cuál es la meta prevista por la teoría no ideal para el caso de las condiciones desfavorables? La respuesta es clara: eventualmente, cada sociedad afectada hoy por condiciones desfavorables debería ser promovida o apoyada para alcanzar las condiciones que hagan posible una sociedad bien ordenada.

Algunos autores han propuesto que se adopte el principio de diferencia o cualquier otro principio liberal de justicia distributivo a fin de afrontar este problema y regular, en consecuencia, las desigualdades económicas en la sociedad de los pueblos ${ }^{51}$. Si bien considero que el principio de diferencia es razonable para la justicia doméstica en una sociedad democrática, no resulta factiblc para tratar el problema general de las condiciones desfavorables entre las sociedades. De una parte, pertenece a la teoría ideal de la sociedad democrática y no está diseñado para nuestro caso. Más aún, existen varias clases de sociedades en la comunidad de los pueblos y no de todas puede esperarse razonablemente que acepten un particular principio liberal de justicia distributiva; e incluso diferentes sociedades liberales adoptan diferentes principios para sus instituciones domésticas. Por su parte, las sociedades jerárquicas rechazan todos los principios liberales de justicia doméstica. No podemos suponer que encuentren aceptables tales principios en sus relaciones con otros pueblos. En nuestra elaboración del derecho liberal de gentes, por consiguiente, los principios liberales de justicia distributiva doméstica no se generalizan para responder a las preguntas sobre condiciones desfavorables.

Confirma lo anterior el hecho de que en una concepción constructivista no existe razón para pensar que los principios aplicables a la justicia doméstica son apropiados también para regular las desigualdades en una sociedad de pueblos. Como vimos al comienzo, cada clase de sujeto - un individuo o una institución, una sociedad política o una sociedad de sociedades políticas- debe gobernarse por sus principios característicos. La identidad de estos principios debe ser establecida mediante un procedimiento adecuado a partir de un correcto punto de partida. Nos preguntamos cómo representantes nacionales debidamente motivados y razonablemente situados unos con respecto a otros serían estimulados para escoger entre los ideales y principios factibles y aplicarlos al sujeto en cuestión. Puesto que el problema y el sujeto son diferentes en cada caso, los ideales y principios adoptados pueden ser también diferentes. Como siempre, el procedimiento completo y los principios que lo sustentan deben ser aceptables tras la debida reflexión.

Aunque no se adoptará ningún principio liberal de justicia distributivo para resolver las condiciones desfavorables, esto no quiere decir que las sociedades más ricas y bien ordenadas no tengan deberes y obligaciones con las sociedades

"Véase Beitz, Political Theory and Intemational Relations, tercera parte, para una sustanciosa discusión. Este principio está definido en Theory, sección 13. No examino el principio aquí porque, como dice mi texto, creo que todos los principios liberales de justicia distributiva resultan inadecuados para el caso en consideración. 
marcadas por tales condiciones. Pues la concepción ideal de la sociedad de los pueblos que sostienen las sociedades bien ordenadas dispone que en su momento todas las sociedades deben alcanzar, o ser ayudadas para alcanzar, las condiciones de posibilidad de una sociedad bien ordenada. Ello implica el reconocimiento y la garantía universales de los derechos humanos, y la satisfacción de las necesidades humanas básicas. Así, la base del deber de asistencia no es cierto principio liberal de justicia distributiva, sino más bien la propia concepción ideal de la sociedad de los pueblos, integrada por sociedades bien ordenadas, de tal suerte que cada pueblo sea miembro pleno y autosuficiente de la sociedad de los pueblos, en capacidad de hacerse cargo de su vida política y mantener instituciones políticas y sociales decentes, como las definidas por los tres requisitos examinados antes ${ }^{52}$.

No intentaré discutir cómo puede alcanzarse lo anterior, ya que el problema de la asistencia económica y tecnológica, como contribución sostenida, es altamente complicado y varía de un país a otro. Más aún, frecuentemente el problema no obedece a falta de recursos naturales. Las sociedades bien ordenadas pueden mantenerse con muy poco; su riqueza está en todas partes: en sus tradiciones políticas y culturales, en su capital humano y tecnología, y en su capacidad de organización política y económica. El problema radica más bien en la naturaleza de la cultura política pública y las tradiciones religiosas y filosóficas que subyacen a sus instituciones. Lo más probable es que en las sociedades más pobres los mayores males sociales sean un gobierno opresivo y unas elites corruptas, al igual que el sometimiento de las mujeres con base en una religión no razonable y la resultante superpoblación en relación con lo que la economia puede sostener decentemente. No hay tal vez sociedad alguna en el mundo cuyo pueblo, razonable y racionalmente gobernado en armonía con su economía y sus recursos, no pueda llevar una vida decente y digna.

Estas observaciones generales indican lo que con frecuencia constituye la fuente del problema: la cultura política pública y sus raíces en lo profundo de la estructura social. La obligación de las sociedades ricas de brindar asistencia para tratar de rectificar las cosas en modo alguno disminuye, tan sólo se hace más difícil. Aquí también, en formas que no necesito describir, el énfasis en los derechos humanos puede ser útil, si está respaldado por otras clases de asistencia, para moderar

${ }^{2}$ El derecho de gentes concuerda con muchas de las ideas de Beitz. Así, él piensa en el principio de diferencia entre sociedades como xun principio de redistribución de recursos que daría a cada sociedad una opción equitativa de desarrollar instituciones políticas justas y una economia capaz de satistacer las necesidades básicas de sus miembros» (p. 141). Dicho principio «asegura a las personas en las sociedades pobres que su mala suerte no les impedirá alcanzar condiciones económicas suficientes para sostener instituciones sociales justas y proteger los derechos humanos» (p. 142). El derecho de gentes acepta las metas que Beitz propone para que las instituciones justas garanticen los dercchos humanos y satisfagan las necesidades fundamentales. Pero, como sugiero en el próximo párrafo, la adversa forma de las personas tiene que ver más con una cultura política distorsionada y corrupla que con la carencia de recursos. Lo único que pemite superar esta desdicha es hacer que las tradicioncs polfticas y la cultura de todos los pueblos sean razonables y capaces de sostener instituciones políticas y sociales justas, y asegurar los derechos humanos. Este es el principio que da pie a los deberes y obligaciones de asistencia. No necesitamos un principio liberal de justicia distributiva para este fin. 
lentamente la opresión de los gobiernos, la corrupción de las elites y la subordinación de las mujeres ${ }^{53}$.

\section{Reflexiones finales}

No he dicho mucho acerca de lo que puede llamarse el fundamento filosófico de los derechos humanos. Ello obedece a que, a pesar de su nombre, los derechos humanos constituyen una clase especial de derechos que se explica por su función en una concepción liberal del derecho de gentes, aceptable por las sociedades bien ordenadas, tanto liberales cuanto jerárquicas. He sugerido, por tanto, cómo puede ser elaborado dicho derecho con base en una concepción liberal de la justicia ${ }^{54}$. Dentro de este esquema, he indicado cómo el respeto de los derechos humanos es una de las condiciones impuestas a todo régimen político para ser admitido como miembro de buena fe en una justa sociedad política de los pueblos. Una vez entendido esto, y una vez entendido cómo un razonable derecho de gentes se deriva de la concepción liberal de la justicia y cómo esta concepción puede tener alcance universal, es perfectamente claro por qué esos derechos cruzan las fronteras culturales y económicas, al igual que las fronteras entre los Estados nacionales u otras unidades políticas. Con nuestras otras dos condiciones, estos derechos determinan los límites de la tolerancia en una razonable sociedad de los pueblos.

"La insistencia en los derechos humanos puede ser útil, como sugiere el trabajo de Amartya Sen sobre las hambrunas. El ha mostrado en Poverty and Famines, Oxford, Clarendon Press, 1981, mediante el estudio empirico de cuatro casos bien conocidos (Bengala en 1943, Etiopia en 1972-1974, Sahel en 1972-1973 y Bangladesh en 1974), que la disminución de los alimentos no es necesariamente la causa principal de la hambruna y a veces ni siquiera se presenta. Pero algunas veces puede ser un factor importante, como en las hambrunas de Irlanda en la década de 1840 o China en 1959-1961. En los casos que estudia Sen puede haberse presentado una caída en la producción de alimentos, pero no habria sido suficiente para crear una hambruna si hubiera habido un gobjerno decente, preocupado por el bienestar de su puehlo y apoyado on un razonable sistema asistencial de carácter público. Para Sen, alas hatmbrunas son desastres económicos y no crisis alimentarias (p. 162). Revelan fallas et la estructura politica y social e incapacidad para adoptar políticas remediables de los efectos de las caidas en la producción alimentaria. Después de todo, se presentarian hambrunas en cualquier democracia occidental moderna si no existiesen esquemas para remediar las pérdidas de ingreso de los desempleados. Un gobierno que sómete a su pueblo a una hambruna evitable viola sus derechos humanos, y si los regimenes bien ordenados no permitietan que ello sucediera, entonces insistir en los derechos humanos significaría presionar en favor de gobiemos decentes y de una decente sociedad de los pueblos. El libro de Sen con Jean Drèze, Hunger and Public Action, Oxford, Clarendon Press, 1989, confirma lo anterior y subraya el éxito de los regímenes democráticos al enfrentar estos problemas. Véase el resumen en el cap. 13, pp. 257-279. Véase también el importante trabajo de Partha Dasgupta, An Inquiry into Well Being and Destifution, Oxford, Clarendon Press, 1993, caps. 1, 2 y 5.

5* Podría preguntarse por qué el derecho de gentes asi formulado se considera liberal si se aplica también a sociedades jerárquicas bien ordenadas. Lo he llamado liberal pớque el derecho de gentes aparece como una extensión de las concepciones liberales de la justicia doméstica. No quiero negar, cmpero, que una sociedad jerárquica bien ordenada pueda tener concepciones de la justicia que se extiendan al derecho de gentes y que su contenido sea el mismo que el de las concepciones liberales. Por ahora, dejo la cuestión abierta. Aspiraría a que hubiera concepciones tales en todas las sociedades jerárquicas bien ordenadas, lo cual ensancharía y fortaleccría el respaldo al derccho de gentes. 
Acerca de estos límites, conviene observar lo siguiente: si partimos de una sociedad liberal bien ordenada que realice una concepción igualitaria de la justicia, tal como la justicia como equidad ${ }^{55}$, los miembros de esa sociedad acogerán, empero, en la sociedad de los pueblos a otras sociedades liberales cuyas instituciones sean considerablemente menos igualitarias. Esto está implícito en nuestro punto de partida con concepciones liberales más generales que la justicia como equidad, como se definió en la sección III. Pero los ciudadanos en una sociedad igualitaria bien ordenada considerarán aún a los regímenes domésticos de esas sociedades como menos compatibles con ellos que el régimen de su propia sociedad.

Esto ilustra lo que ocurre cuandoquiera que el ámbito de tolerancia se extiende; los criterios de razonabilidad se relajan ${ }^{56}$. En el caso en cuestiơn, nos proponemos incluir a sociedades distintas de las liberales como miembros de buena fe en una razonable sociedad de los pueblos. De ahí que cuando nos desplazamos hacia estas sociedades, sus regímenes domésticos son menos, con frecuencia mucho menos, compatibles con nosotros. Ello plantea el problema de los límites de la tolerancia. ¿Dónde han de ser trazados estos límites? Resulta claro que los regímenes tiránicos y dictatoriales deben ser proscritos, al igual que Estados expansionistas como los de las guerras religiosas, por razones liberales básicas. Las tres condiciones necesarias de un régimen bien ordenado -que respete los principios de la paz y no sea expansionista, que su sistema jurídico sea legítimo a los ojos de su propio pueblo y que respete los derechos humanos fundamentales- constituyen una respuesta sobre dónde se hallan estos límites. Estas condiciones nos indican el horizonte más allá del cual no podemos ir.

Hemos discutido cuán lejos han estado siempre y se encuentran hoy muchas sociedades del mundo de cumplir estas tres condiciones para ser miembros de buena fe de una razonable sociedad de los pueblos. El derecho de gentes suministra la base para juzgar la conducta de cualquier régimen existente, liberal o no liberal. $Y$ puesto que nuestra versión del derecho de gentes se deriva de una concepción liberal de la justicia, debemos abocar la cuestión de si el derecho liberal de gentes es etnocéntrico y simplemente occidental.

Para ello, recuérdese que al formular el derecho de gentes supusimos que las sociedades liberales se conducen hacia otras sociedades desde el punto de vista de su propia concepción política liberal. Al considerar sensata esta concepción y al reunirse en ella todos los criterios que ahora pueden aplicar, ¿de qué otra manera han de proceder? Frente a la objeción de que proceder así es etnocéntrico o simplemente occidental, la respuesta es: no, no necesariamente. Si es así, depende del contenido de la concepción política que las sociedades libcrales abrazan tan pronto como está en capacidad de suministrar al menos un bosquejo del derecho de gentes.

Al observar el esquema de ese derecho deberíamos advertir la diferencia entre él y el derecho de gentes entendido por Estados religiosos y expansionistas que

\footnotetext{
59 Los tres elementos igualitarios son el justo valor de los derechos políticos, la justa igualdad de oportunidades y el principio de diferencia, de acuerdo con mi Theory of Justice.

* En el caso doméstico, de manera paralela estimamos razonables muchas doctrinas comprensivas que, en nuestro propio caso, no veriamos como dignas de seria consideración. Véase Political Liberalism, Conferencia II, sección 3.1 y la nota de pie de página.
} 
rechazan la concepción liberal. La concepción liberal demanda de otras sociedades sólo lo que razonablemente puedan dar, sin someterse a una posición de inferioridad ni mucho menos a una de dominación. Resulta crucial que una concepción liberal del derecho de gentes no demande a las sociedades jerárquicas bien ordenadas que abandonen sus instituciones religiosas y adopten otras liberales. Es verdad que en nuestro esquema supusimos que las sociedades tradicionales afirmarian el derecho de gentes que fuera acogido entre sociedades liberales justas. Ese derecho tiene entonces alcance universal: demanda de las otras sociedades únicamente lo que puedan aceptar una vez que estén preparadas para actuar en una relación de igualdad con todas las demás sociedades y una vez que sus regímenes acepten el criterio de legitimidad a los ojos de su propio pueblo. ¿En qué otras relaciones pueden una sociedad y su régimen esperar razonablemente actuar?

Más aún, el derccho liberal de gentes no justifica sanciones económicas o presión militar contra sociedades jerárquicas bien ordenadas para que cambien sus formas de actuar, siempre que respeten las reglas de la paz y sus instituciones políticas cumplan las condiciones esenciales que hemos revisado. No obstante, si estas condiciones se violan, puede justificarse la presión extema de una clase u otra según la severidad y las circunstancias del caso. La preocupación por los derechos humanos debería ser parte de la política exterior de las sociedades liberales y jerárquicas.

Al volver sobre nuestra discusión, recordemos que, además de sugerir cómo el derecho de gentes puede derivarse de las concepciones liberales del derecho y la justicia, nuestro propósito ulterior era plantear la sustentación del liberalismo político para una más amplia sociedad mundial, una vez que una concepción política liberal de la justicia se extiende al derecho de gentes. Preguntábamos en concreto: ¿Qué forma asume la tolerancia de las sociedades no liberales en este caso? Si bien los regímenes tiránicos y dictatoriales no pueden ser admitidos como miembros de buena fe en una razonable sociedad de los pueblos, no a todos los regímenes se les puede exigir de manera razonable que sean liberales. Si así fuere, el derecho de gentes no expresaría el principio de tolerancia, que es propio del liberalismo frente a otras formas de ordenar la sociedad. Una sociedad liberal debe respetar a las otras sociedades organizadas conforme a doctrinas comprehensivas, siempre que sus instituciones políticas y sociales cumplan ciertas condiciones que conduzcan a adoptar un razonable derecho de gentes.

No he tratado de presentar un argumento contra esta conclusión. Me ha parecido claro que si otras sociedades no liberales respetaban ciertas condiciones, como los tres requisitos considerados en la sección IV, serían aceptadas por las sociedades liberales como miembros de buena fe de una sociedad de los pueblos. Desde el punto de vista político, no habría caso en atacar a estas sociedades no liberales, mediante presión militar o sanciones económicas, para que revisaran sus instituciones. El ejercicio de la crítica en las sociedades liberales seria enteramente consistente con las libertades y la integridad cívicas de esas sociedades.

¿Qué concepción de la tolerancia de otras sociedades expresa el derecho de gentes? ¿Y cómo se relaciona con el liberalismo político? Si debiera preguntarse si, moralmente hablando, las sociedades liberales son mejores que las sociedades jerárquicas y si, por tanto, el mundo sería mejor si todas las socicdades fuesen 
liberales, quienes sostienen una doctrina liberal comprensiva podrian responder de manera afirmativa. Pero esa opinión no justificaría la pretensión de desterrar a los regímenes no liberales. No tendría ninguna fuerza en lo que, como cuestión de justicia, tales regímenes podrían hacer en el campo de la política. La situación es paralela a la tolerancia de otras concepciones del bien en el terreno doméstico. Quien sostiene una doctrina liberal comprehensiva puede decir que la sociedad de los otros sería mejor si compartiera su punto de vista. Esta postura puede ser errónea en sus propios términos, pues las otras doctrinas pueden desempeñar una función de moderación y de equilibrio en el amplio contexto de las creencias y de las convicciones, y pueden aportar hondura y riqueza a la cultura de la sociedad. La afirmación de la superioridad de una particular doctrina comprehensiva es enteramente compatible con la afirmación de una concepción política de la justicia que no impone aquella doctrina $y$, por tanto, con el liberalismo político mismo.

El liberalismo político sostiene que las doctrinas comprehensivas no tienen más que un lugar limitado en la política liberal democrática: las cuestiones constitucionales fundamentales, concernientes a los derechos y las libertades de carácter básico, han de ser convenidas según una concepción política pública de la justicia, encarnada en las concepciones políticas liberales y no en esas doctrinas más amplias. Dado el pluralismo de las sociedades democráticas —un pluralismo que debe ser visto como el resultado del ejercicio de la razón humana bajo instituciones libres y que sólo puede ser suprimido mediante el uso opresivo del poder estatal-, sostener esa concepción pública y las instituciones políticas básicas que la desarrollan constituye el más razonable fundamento de la unidad social a nuestra disposición.

El derecho de gentes, como lo he esbozado, es simplemente la extensión de estas mismas ideas a la sociedad política de los pueblos bien ordenados. Ese derecho, que resuelve las cuestiones constitucionales fundamentales y los asuntos de justicia básica en la sociedad de los pueblos, debe estar fundado también en una concepción política pública de la justicia y no en una doctrina moral, filosófica o religiosa comprehensiva. He bosquejado el contenido de dicha concepción política y he tratado de explicar cómo podría ser suscrita por sociedades bien ordenadas, tanto liberales cuanto jerárquicas. Salvo como base de un modus vivendi, las sociedades expansionistas de cualquier signo no podrían suscribirla; pero en principio no existe solución pacífica para su caso, excepción hecha de la dominación de un solo lado o la paz del agotamiento. 